УДК 82.091

DOI: $10.17223 / 24099554 / 9 / 7$

\title{
А.Г. Янкус
}

\section{СМЕРТЬ СУБЬЕКТА КАК СМЕРТЬ ЧИТАТЕЛЯ В РОМАНЕ А. КОРОЛЕВА «ДОМ БЛИЗНЕЦОВ»}

\begin{abstract}
Рассматривается роман Анатолия Королева «Дом близнецов» (2016). Детективная фабула уподобляет структуру романа лабиринту, сюжет расследования оборачивается поиском ответа на вопрос о бытии и положении в нем субъекта. Отграниченное от внешнего мира пространство, в котором разворачиваются события романа, оказывается метафорой пространства культуры, населенного двойниками - похожими на истину, но не истинными смыслами, сменяюшими друг друга, но не ведущими к познанию истины. Вступивший на эту территорию персонаж, субъект восприятия текстов культуры, поглощается искусственным конструктом - читатель оказывается порождением текста. Витальная сила личности сопротивляется этому, но отказ от мира текстов также ведет к смерти субъекта в смыслах-итампах повседневности.

Ключевые слова: Анатолий Королев, «Дом близнецов», постмодернизм, философская проза, познание, смерть субъекта, читатель, симуляция, культура, текст.
\end{abstract}

Роман Анатолия Королева «Дом близнецов» продолжает традицию русской философской прозы, сочетающей пластическое и интеллектуальное начало. Детективная фабула встраивает жизнеподобное событие в обстоятельства с элементами фантастического; таинственное хотя и получает объяснения, но они выходят за рамки реально возможного. Так создается семантическая двуплановость изображаемого, знаковая игра, необходимая для моделирования онтологии и культуры через столкновение разных версий бытия, текстов о бытии. Отношения персонажей, событийный ряд и пространственная среда получают статус авторских вариантов действительности; персонажи также наделены собственными взглядами на мир. Столкновение версий персонажей не подавляется повествовательной (авторской) оценкой, а авторская символика изображаемого не сводится к однозначной 
интерпретации. Поэтому роман открыт разным трактовкам смысла, как и само бытие, моделирование и познание которого определяют авторскую стратегию.

Главный герой романа, сыщик Валентин Драго, должен отправиться в частную клинику «Хегевельд», чтобы сообщить находящимся там близнецам, что их умершая мать оставила им наследство. Поселившись в отеле рядом с закрытой для посторонних посетителей лечебницей, он знакомится с Ватиканским профессором, архивариусом из Турина доном Клавиго, фотографически похожим на Валентина. Клавиго должен был доставить в Хегевельд нечто ценное, и, когда он внезапно умирает, Валентин попадает на территорию клиники как ожидаемый гость профессор дон Клавиго.

Фабула строится как хроника пребывания Валентина (Клавиго) в Хегевельде в течение семи дней, каждому из которых посвящена глава романа. В эти дни происходит познание-расследование Валентином мира Хегевельда в поисках близнецов. Трудность заключается в том, что Хегевельд населен подобиями-двойниками, из которых трудно выделить подлинных, природных близнецов. Параллельно происходит расследование-разоблачение обитателями и хозяином Хегевельда самого Валентина как двойника Клавиго, не имеющего права доступа к тайному знанию.

Семь дней - календарный цикл изменений, после которого происходит повторение последовательности, т.е. некий мифический круг познания должен привести к открытию закона мира. Каждая глава делится на три части, которые показывают разные ситуации видения реальности, метаморфозы представлений субъекта об окружающей действительности. Утро и день создают иллюзию видимости и понятности окружающего: Валентин осматривает пространство Хегевельда, разговаривает с теми, кто создает материальную среду (с садовником, кутюрье). На ужинах присутствуют хозяин и обитатели клиники, а также гость, который задает тему беседы, каждый день - новый. Центральной ситуацией ужинов становятся философские диспуты, столкновение разных версий жизни, смерти, бессмертия, веры, а также их проверка текстом сакральной книги, которую вез в Хегевельд архивариус Клавиго. Ночной Хегевельд открывается не то во сне, не то в пограничном состоянии героя: «только-только сон набрал в легкие забытья сонм сновидений, как в дверь постучали» [1. С. 90]. Обнаруживается скрытая, ирреальная сторона Хегевельда и его обитателей, 
противоречащая очевидному дневному образу; корректируется интуитивное представление Валентина о его существе.

Хегевельд (от нем. Hegewald - «заповедный лес») - частная закрытая клиника, которая гарантирует полное избавление от любой болезни: «Наша методика проста, мы замещаем тело больного его здоровой копией» [1. С. 51].

Территория клиники - закрытое пространство; граница оказывается непроницаемой для героя, пока он остается самим собой [2. С. 88]. Проникновение в Хегевельд окружено атрибутикой путешествия в Царство Мертвых: молчаливый перевозчик, встречающие гостя при въезде черные собаки. Но Хегевельд также и пространство карнавальной перевернутости, игры: его обитатели меняются ролями (костюмер Мандарин, играющий роль лакея, говорит Валентину: «...случаются перестановки, если хозяин не в духе. Кстати, иногда он садится на мое место, а меня сажает на свое. И я могу приказать, что угодно» [1. С. 50]), переодеваются, разыгрывают спектакли и т.д. Ужины, занимающие основную часть повествования, совмещают семантику пира, философской беседы и карнавала, игры:

Веселье и игра были неразрывно связаны с глубинной семантикой традиционного застолья, поскольку центральная его идея заключалась в наделении всех присутствующих гостей «долей», определении «судьбы». В надежде получить свою удачу, свой шанс участники застолья вступали в игровое состязание, в «тонкое общение с судьбой», которое и является сущностью любой игры [3. С. 50].

В центре Хегевельда расположена оранжерея для выращивания мандрагоры. Аура, создаваемая этим растением, распространяется на всю территорию клиники и погружает ее гостей и обитателей в измененное сознание, в котором они получают ранее недоступные знания, начинают понимать незнакомые им языки. Под действием этого эффекта Валентин начинает слышать Голос Мандрагоры как голос Другого в себе.

Образ пространства, который есть «не просто среда, в которой размещены предметы и происходят события, но образ мира, в котором взаимодействуют образы реальности и сознания» [4. С. 50], раскрывается в смысловых отношениях с сюжетом. Пространство Хегевельда является метафорой «пространства культуры», и его цель преодоление законов бытия, прежде всего - смерти, болезни, неповторимости. Оно подчеркнуто вторично: меню ужинов, помещения, персонажи воспроизводят бывшие события, связанные либо с известной 
личностью из мира культуры, либо со значимым историческим событием. Внутреннее убранство клиники описывается как излучающее «шик нешуточной власти и чары богатства» [1. С. 22]: мир Хегевельда это мир аристократического блеска, противопоставленного серой повседневности главного героя.

Владелец клиники - эксцентричный «Хозяин Хегевельда» Виктор фон Боррис, именующий себя «Князь». Имя Виктор переводится как «победитель», Борис - от старославянского Борислав, «славный в борьбе». В имени хозяина клиники заложено противопоставление: с одной стороны, борьба, которая длится; с другой - победа как конец борьбы. Удвоенное «р» во второй части указывает на двоение, которое не позволяет этой борьбе закончиться. Фамильная приставка «фон», помимо указания на принадлежность к древнему роду (в данном случае - к миру культуры), может прочитываться как слово «фон», т.е. декорации, в которых данная борьба разворачивается.

Титул «Князь» отсылает к одному из имен Дьявола в христианской традиции. Он был низвержен на землю, став после падения «князем тьмы», отцом лжи и возглавив мятеж против Бога: «Он был человекоубийца от начала и не устоял в истине, ибо нет в нем истины. Когда говорит он ложь, говорит свое, ибо он лжец и отец лжи» (Ин. 8: 44) [5. C. 1141].

Князь в романе А. Королева бросает вызов мироустройству, в котором несовершенство и смерть. В его клинике пытаются излечить от абсурда бытия, его несовершенства и непостижимости, опираясь на положения науки, погружая в мифы культуры, меняя сознание с помощью мандрагоры. Хегевельд - антитеза Дома Бытия, если использовать аллюзии на хайдеггеровский концепт. Созданное изолированное пространство Хегевельда - это построенное по текстам культуры пространство, которое комфортно, и обитатели-близнецы не готовы покинуть его, вернуться в свой реальный дом. Фабульно это показано в отказе близнецов Фарро от дома, оставленного им в наследство. Но и другие персонажи, чувствуя интенцию к миру за пределами Хегевельда, остаются в комфортном доме иллюзий, более понятном, чем реальность. Это пространство мифологизированного мандрагорой и идеями культуры сознания; у всех его обитателей, и прежде всего у князя, есть потребность в обсуждении версий бытия, поэтому философские трапезы - центр жизни Хегевельда.

Королев создает не модернистское погружение в иррациональное мироощущение, а постмодернистское скептическое перебирание 
версий бытия, зафиксированных в идеях, текстах. Поэтому остается незавершенным познание бытия обитателями Хегевельда и Валентином, поставленным перед выбором между реальностью и Домом-копией текстов культуры.

При метонимическом переносе семантики пространства культуры на конкретное пространство Хегевельда можно выстроить следующую схему: читатель (Валентин), автор-демиург (Князь), произведение (Хегевельд). В таком ракурсе «Дом близнецов» является метароманом, с той разницей, что традиционно этот тип прозы включает сюжет создания произведения [6. С. 49], в то время как роман А. Королева основан на сюжете его прочтения. Безусловно, прочтение должно завершаться пониманием смысла текста, а смысл Хегевельда - попытка исправить бытие, изменить онтологию. Но мы в этой статье ограничимся уровнем профанного персонажа, который только приближается к пониманию культуры как лабиринта и устремляется в реальность, как ему кажется, более конкретную и понятную.

Проникновение на территорию Хегевельда под чужим именем превращает сыщика, занятого разгадыванием фактов реальности, в Читателя. Персонаж как детектив-читатель эмпирической жизни Хегевельда пытается понять принцип организации жизни и мыслиидеи его обитателей, повторяющие друг друга и цитирующие авторов прошлого, но и сам он вовлекается в текст Хегевельда.

Во время прогулки по территории клиники Валентин находит бинокль, с помощью которого рассматривает Хегевельд с крыши дома для гостей. Заканчивается эпизод следующим образом: «Тут кто-то пустил прямо в окуляры бинокля солнечный зайчик. Вспышка света была так сильна, что озарила пещеру черепа» [1. С. 55]. С одной стороны, это можно соотнести с положением Хайдеггера о человеке как «просвете в бытии», с другой - образ пещеры, стены которой озаряются светом, отсылает к платоновской концепции. Но если у Платона свет, проникающий в пещеру, - это свет из мира эйдосов, идеальных сущностей, достигаемых в умопостижении, в отвлечении от чувственного постижения вещей [7. С. 349], то в романе Королева этот свет результат детской игры (солнечный зайчик в бинокль наблюдателя пустила девочка Катя). Идеи, которые может предложить Хегевельд, всего лишь игра.

Это завершает открытие сокрытого бытия. Обнаружив источник света, Валентин теряет интерес к Хегевельду, но в то же время эпизод 
становится моментом инициации: так Читатель становится порождением текста (семантика имени «Клавиго» восходит к слову «клавиша» - часть механизма, нажатие на которую извлекает либо звук (в музыке), либо новый знак (в печатной машинке)). В широком смысле Читатель - это «то пространство, где запечатлеваются все до единой цитаты, из которых слагается письмо; текст обретает единство не в происхождении своем, а в предназначении, только предназначение это не личный адрес; читатель - это человек без истории, без биографии, без психологии, он всего лишь некто, сводящий воедино все те штрихи, что образуют письменный текст» [8. С. 390].

Герою открывается ряд близнечных и двойнических пар, населяющих Хегевельд. Множественность похожих на истину, но не истинных смыслов (симулякров) не позволяет выстроить единую картину бытия.

Двойничество и близнечество представляют разные типы парных отношений: с одной стороны - «противоречие, двойственность, противопоставление», с другой - «парность, удвоение, четность» [9. C. 178]. Обе группы неоднородны: так, близняшки Магда и Герда во многом противопоставлены друг другу (в частности, одну из них устраивает пребывание в Хегевельде, а другая пытается сбежать), а близнецы Брат-1 и Брат-2, докладчики, представляющие постструктуралистскую картину мира, абсолютно тождественны. Близнецы, которых ищет Валентин, природно неравновелики (в теле Фарро - его сиамский близнец).

По-разному организуются и пары двойников. Предсказательница Пифия и Кукла Катя не имеют внешнего сходства, но они дополняют друг друга: вторая является голосом первой; Князь и его секретарь внешне неотличимы, второй является карнавальным перевертышем первого.

Кроме того, цельность двойнических и близнечных пар нарушается во время ночных сцен, открывается оборотная сторона индивида, созданного по стереотипам культуры. Так, секретарь Князя оказывается переодетой и загримированной Магдой.

В пяти диспутах о природе Бытия, которые ведутся во время ужинов, приглашенные докладчики предлагают свои версии мироустройства. Князь или кто-то из обитателей выдвигает контраргументы, обнаруживая относительность всякой версии. Князь выступает арбитром, сталкивающим разные картины мира и вносящим свои коррекции, 
но не навязывающим ценностную вертикаль, а аргументирующим свои методы «лечения» пациентов и самой реальности в отдельном замкнутом пространстве. Князь - не тоталитарный Автор классического типа, но постмодернистский Скриптор, смешивающий разные тексты, равно не принимаемые за истинные.

Порядок разворачивания картин мира соответствует их смене в истории человечества, меняется и роль Князя в беседе, отражая особенности позиции Автора в тот или иной период. Так, в первой беседе, в которой представлена религиозная картина мира, Князь участвует наравне с докладчиком (знатоком каббалы равви Барухом), между ними не возникает спора: Автор транслирует и варьирует религиозный взгляд на мир, корректируя понятие «Свет» понятием «Блеск». Свет - образ смысла, ниспосланного в мир Творцом, но восприятие света оказывается невозможным, человек способен лишь ловить отблески смысла, отражения света. Рационалистическая картина мира доктора Соломона Зинглера (второй докладчик) подавлена голосом Князя, противопоставляющим позитивистской установке непознаваемость бытия, его вечную загадку. Тем более что научные знания меняются, обнаруживая свою относительность.

Подобные коррекции, аннигилирующие предлагаемые версии, происходят и дальше, по мере разворачивания модернистской, структуралистской и постструктуралистской картин мира.

Дискутирующие за ужином - бывшие пациенты клиники, излеченные от тяги к смерти («Клуб бывших самоубийц»). Лечение, которое предлагает Хегевельд - готовые идеи, концепции, принимаемые и тут же дискредитируемые, чтобы не подчинить человека, не дать ему познания истины, лишающей надежд и смысла. Принятие той или иной картины мира временно - и в культуре, и в сознании индивида. Постоянна смена или подмена близнечной, вариативной идеей, что ведет не только к смерти автора, но и к смерти читателя как смыслообразующего субъекта понимания текста: «Забыв Баруха, больной стал хасидом и встал на путь исцеления», - говорит Князь о вылеченном раввине [1. С. 107]. Имя как знак личности подменяется ложной идентичностью - принадлежностью к хасидизму.

Смерть субъекта - «метафорический термин для обозначения одного из двух полюсов амбивалентной тенденции размывания определенности субъект-объектной оппозиции в рамках постмодернистской программы преодоления традиции бинаризма» [10. С. 774]. 
Дневной способ поведения в Хегевельде связан с властью внешней упорядоченности, не деспотией, но принятием правил игры. Это смерть субъекта вследствие подчинения надличным структурам, уровню Супер-Эго. Ночь - время подчинения инстинктам, подсознанию (Оно). Но подсознание архетипично, внесубъектно. Не случайно погружение в сексуальную свободу под действием мандрагоры оборачивается превращением героев в собак для ночной охоты-вакханалии.

Структура романа двоится: остросюжетная фабула, названная Королевым «манком сюжета», и «семь диспутов о природе реальности» [11] сводятся во время застолья. Поглощение пищи и поглощение смыслов, вначале строго разделенные (еда во время первого ужина подается после окончания беседы), постепенно смешиваются, на третьем ужине прием пищи начинается во время речи докладчика. На последнем же ужине к столу подается книга Стивена Хокинга, обработанная поваром таким образом, что ее страницы съедобны. Герой - только слушатель и транслятор (читатель) текстов культуры, но не ее смыслов. Он не создает своего текста, не становится автором. Хегевельд предлагает не сакральное знание, но бесконечный пир духа.

Поскольку пространство Хегевельда может рассматриваться и как образ «пространства культуры», и как метафорический образ художественного произведения, Валентин уподобляется либо человеку, вступившему на территорию культуры, либо читателю, погрузившемуся в мир художественного текста. В таком случае Смерть субъекта - это смерть читателя, субъекта восприятия текстов культуры.

Королев отсылает реального читателя к роману У. Эко «Имя розы»: семь глав, посвященных семи дням творения; начало обоих романов - библейская формула «В начале было слово...»; сюжет о детективе, проникающем в условное пространство для разгадывания загадки; форма интеллектуального романа под маской детектива. Ю.М. Лотман сравнивает роман «Имя розы» с лабиринтом:

$<\ldots>$ образ лабиринта - один из сквозных для самых разных культур символов - является как бы эмблемой романа У. Эко $<\ldots>$ в отличие от паутины, лабиринт принципиально асимметричен. Но каждый лабиринт подразумевает своего Тесея, того, кто «расколдовывает»его тайны и находит путь к центру [12. С. 656].

Опьяненный настойкой мандрагоры, Валентин погружается в состояние лунатизма, в котором он способен перемещаться, балансируя, по акведуку. С того момента, как персонаж впервые совершает такую 
прогулку, автор использует слово «виадук» (фр. viaduc, от лат. via - дорога, путь, duco - веду). Система акведуков сравнивается в романе именно с паутиной, центр которой - дом Князя; она симметрична, расположена над землей; тогда как в лабиринте не видно нужного пути, акведук весь обозревается путешествующим по нему. Пройдя лабиринт, герой (Тесей, Вильгельм в «Имени розы») находит центр, символически - искомую истину. В романе Королева Валентин разгадывает с помощью виадука загадку близнецов, но дом, в котором он раскрывает тайну Фарро, не является центром анти-лабиринта, он находится на периферии. Центр - особняк Князя, выстроенный в форме Сфинкса, в котором проходят ужины и который для близнецов стал заменой собственного дома, местом исполнения чудесной музыки. Поиск близнецов оказался не разгадкой тайны, а погружением в зацикленный процесс разгадывания тайны искусственной жизни, в которой люди спасаются от отчаяния и самоубийства.

На входе в помещение, где герой находит близнецов и раскрывает их тайну, он замечает две статуи: «бронзовая Помона с яблоками в каждой ладони. Работа Майоля» и «металл, скомканный руками экспрессиониста. Бронзовый мальчик работы Барлаха» [1. С. 277]. Помона римская богиня древесных плодов и изобилия, супруга Вертумна. У Овидия присутствует миф о том, как Вертумн добился взаимности Помоны: сначала он прибегал к разного рода превращениям, но завоевал Помону, только явившись в своем настоящем образе. Так и секретарь Князя советует Валентину «быть тем, кто ты есть».

Человек в творчестве Эрнста Барлаха - бесконечно страдающее существо, и воплощение страдания в пластическом образе становится способом постижения закона бытия: «Направление внутрь (к скрытому - сокровенному) есть в то же время движение ввысь - к духу и его царству» [13. С. 788].

Не менее важны здесь имена Аристида Майоля, французского скульптора-импрессиониста, и Эрнста Барлаха, немецкого экспрессиониста. Голос Мандрагоры, когда Валентин блуждает по виадуку и когда он уже стоит на земле перед жилищем Фарро, между двумя статуями, неоднократно напоминает: «Держи равновесие». Соблюдение баланса между экспрессивной и импрессивной установками - суть отношения между автором и героем:

Переживание тела из себя - внутреннее тело героя объемлется его внешним телом для другого, для автора, эстетически оплотняется его 
ценностною реакцией. Каждый момент этого внешнего тела, объемлющего внутреннее, носит как эстетическое явление двоякую функцию: экспрессивную и импрессивную, которым соответствует двоякая активная установка автора и созерцателя [14. С. 60].

Умение балансировать на виадуке, охарактеризованном Князем как «позвоночник моей Грезы», - это метафора пребывания не только в Хегевельде, но и в реальности и культуре вообще. В Хегевельде герою приходится балансировать между предложенными картинами мира, не принимая ни одну из них, но и не отказываясь от них вовсе: побег с территории клиники заканчивается для Валентина смертью.

К третьему ужину в Хегевельд доставляется книга «Сад Исполнения Желаний». Это источник некоего сакрального знания, которое зашифровано, так что читать книгу способен только Валентин, опьяненный парами мандрагоры. Эта ситуация также повторяет сюжет романа «Имя розы», о котором Ю.М. Лотман пишет: Вильгельм Баскервильский в монастыре «занят расшифровками. И в прямом смысле - чтением закодированной рукописи, - и в переносном» [12. С. 660]. Разница в том, что Вильгельм делает это осознанно, Валентин же понятия не имеет, как рукопись читается, он не владеет никаким кодом, книга сама говорит сквозь него, он - «инструмент языка».

Такое смещение раскрывает полемику А. Королева с Умберто Эко о роли читателя или субъекта восприятия вообще: вместо критически настроенного субъекта, обладающего спасительной иронией и возможностями интерпретации, здесь - герой-профан. Даже когда Валентин при помощи Книги или навеянных мандрагорой знаний включается в дискуссию, он представляет не свое знание, а знание, идущее сквозь него. Читатель оказывается не адресатом и даже не гостем, но порождением текста.

Такое прочтение романа не противоречит другому: положение Валентина в Хегевельде - заброшенность человека в мир, тайну которого он должен разгадывать. При такой интерпретации более тесной становится связь романа с философской системой Мартина Хайдеггера, отсылка к которому - реконструированный на территории клиники 1927 г., когда был издан труд «Бытие и время». Валентин стремится не столько к тайне Бытия, не столько к текстам о Бытии, сколько к Бытию-в-мире [15. С. 114-126]. Когда Валентин один, ему не перед кем играть роль дона Клавиго, но нет и того, по отношению к кому он мог бы определить себя как Валентина, провести границу 
между собой и Другим. Границы между собой и миром он провести не может, так как не отделен от мира, а помещен в него, является его частью в положении «тело среди тел».

Поиск ответа на вопрос о субъекте, поставленный Хайдеггером, смысловая фабула романа «Дом близнецов». Королев постулирует возможность множества ответов. Так, он перебирает варианты голосами докладчиков и обитателей Хегевельда, противопоставляет им текст квази-сакральной книги. Другие версии зашифрованы в фабуле романа: противопоставление дневного и ночного знания, противопоставление Востока и Запада, всевозможные комбинации двойников, перевертышей и близнецов.

Две линии интерпретации соединяются постмодернистской концепцией «мир как текст». Когда книга «Сад Исполнения Желаний», ценный артефакт внутри Хегевельда, оказывается за его границами, она превращается в обыденный объект, пособие для цветоводов: «Он развернул страницы. Вместо таинственной рукописной абракадабры - плоский серийный шрифт... какие-то банальные фотографии цветочных ваз» [1. С. 284].

Таким образом, условное пространство Хегевельда является локальной версией бытия, конструктом из набора вторичных объектов и смыслов. Ложное одухотворение, которое он предлагает - опьянение парами мандрагоры, это отказ субъекта от себя, от своего знания о мире, от положения вне дискурса. То, что Хегевельд является клиникой, показывает, как искусственный конструкт может вылечить, преподнеся одну из готовых истин о мире. Чтобы принять такое лечение, субъект должен отказаться от себя («Главное - ваша готовность рискнуть и стать другим веществом» [Там же. С. 51] - фраза из рекламной брошюры Хегевельда). Истины двоятся, переодеваются, меняются местами, множатся. Субъект ищет симбиоза, но слитые воедино близнецы - такие же пленники Хегевельда, отказавшиеся от самости.

Здоровая личность (Валентин от лат. valens - «здоровый, сильный») сопротивляется смерти, бежит от игры в готовые смыслы. Первую попытку побега персонаж предпринимает, скрывшись на корабле нудистов, затерявшись среди голых тел и занимаясь сексом. Это попытка противопоставить условности Хегевельда телесность. Но побег не удается. Удачная попытка бежать - по кабелю электропередачи, что связано с тем же умением балансировать. Но, выбравшись, 
герой убивает себя. Эту смерть можно трактовать и как отказ от Хегевельда, и как окончательную смерть субъекта, готового раствориться в повседневности.

Но в романе есть другой вариант финала: пистолет дает осечку, и Валентин возвращается в Хегевельд, где его встречает Князь: «Ваша пуля у меня, - сказал князь. И показал раскрытую ладонь» [1. С. 290]. Однажды приобщившийся к миру культуры не может отказаться от него, даже осознав недостижимость конечного знания о мире. Когда герой попадает при побеге в капкан, он оказывается за пределами Хегевельда, но на территории Князя остается его пятка, «ахиллесова пята» вошедшего в культуру читателя.

\section{Литература}

1. Королев А.В. Дом близнецов : роман-детектив. М. : ArsisBooks, 2016. 296 c.

2. Лотман Ю.М. Внутри мыслящих миров. Человек-текст-семиосфера-история. М. : Языки русской культуры, 1999. 896 с.

3. Морозов И.А., Слепиова И.С. Круг игры. Праздник и игра в жизни севернорусского крестьянина (XIX-XX вв.). М. : Индрик, 2004. 920 с.

4. Рыббальченко Т.Л. Образный мир художественного произведения и аспекты его анализа : учеб.-метод. пособие. Томск : Изд-во Том. ун-та, 2012. 130 с.

5. Библия. Книги Священного Писания Ветхого и Нового завета : канонические. М. : Рос. Библейское о-во, 1994. 1254 c.

6. Липовецкий М.Н. Русский постмодернизм: очерки исторической поэтики. Екатеринбург : УрГПУ, 1997. 317 с.

7. Платон. Сочинения : в 4 т. / под общ. ред. А.Ф. Лосева и В.Ф. Асмуса. СПб. : Изд-во С.-Петерб. ун-та; Изд-во Олега Абышко, 2007. Т. 3, ч. 1. 752 с.

8. Барт Р. Избранные работы: Семиотика. Поэтика. М. : Прогресс, 1994. 616 с.

9. Гаврилова Е.Г. Отражение национального мироощущения в паремиях с компонентом-числительным два // Инновации. Интеллект. Культура : материалы XXII Bсеpoc. (с междунар. участием) науч.-практ. конф. Тюмень : Тюмен. индустриальный ун-т, 2015. C. $178-180$.

10. Постмодернизм : энциклопедия / сост. и науч. ред.: А.А. Грицанов, М.А. Можейко. Минск : Интерпрессервис : кн. дом, 2001. 1038 с.

11. Королев А.В. Разодранный мех и ветер времени : беседа с Г. Заславским // Независимая газета. 26.02.2015. URL: http://www.ng.ru/ng_exlibris/2015-02-26/2_persona.html

12. Лотман Ю.М. Выход из лабиринта // Эко У. Имя розы. М. : Книжная палата, 1989. $496 \mathrm{c}$.

13. Михайлов А.В. Языки культуры : учеб. пособие по культурологии. М. : Языки русской культуры, 1997. 912 с.

14. Бахтин М.М. Автор и герой в эстетической деятельности // Бахтин М.М. Эстетика словесного творчества. М. : Искусство, 1979. С. 9-191.

15. Хайдеггер М. Бытие и время. М. : Академический проект, 2011. 460 с. 
THE DEATH OF A SUBJECT AS THE DEATH OF A READER IN THE NOVEL HOUSE OF TWINS BY ANATOLY KOROLEV

Imagologiya i komparativistika - Imagology and Comparative Studies, 2018, 9, pp. 111-124. DOI: 10.17223/24099554/9/7

Andrey G. Yankus, Tomsk State University (Tomsk, Russian Federation). E-mail: ioliveyra@yandex.ru

Keywords: Anatoly Korolev, House of the Twins, postmodernism, philosophical prose, cognition, death of subject, reader, simulation, culture, text.

Anatoly Korolev's novel House of the Twins is considered as a continuation of traditions of Russian philosophical prose in postmodern poetics. Relationships between the characters, the events and the space itself acquire the status of the author's variants of the reality. The confrontation between different versions of the characters is not suppressed by the author's view and the symbolism of the portrayed cannot be interpreted unambiguously.

The detective plot makes the novel structure look like a maze. It turns out that the investigation of a particular case transforms into a search for answers about the existence and the subject's place in it. The analysis of the system of characters and patterns of space in the novel allows comparing the central topos (the private Hegeweld Clinic, where you can be cured of craving for death) with a cultural space, and its owner with the author himself. The cultural space is inhabited with doubles. Firstly, they are not connected, they tell us about different aspects of existence. Secondly, each version of existence forks and, therefore, is depreciated by its alternative. No one possesses true meanings, the versions of existence change during philosophical disputes ("feasts") and do not lead to the knowledge of truth.

The main character is a detective who penetrates onto Hegeweld's territory using a false name. He is considered as a Reader, the subject of perception of the world as text. When he gets onto the territory of the clinic, he accidentally becomes a listener of five disputes about the nature of existence and takes part in them. He tries to understand the ideas of the clinic inhabitants (who quote authors of the past), and he starts to be involved in Hegeweld's text. The Reader becomes a product of the locus text, which is analysed as a variant of the post-structuralistic concept of the Death of a Subject.

As an ignoramus character and a detective (investigator) at the same time, the main character himself becomes a double of the reader and keeper of the sacred book, which was taken to Hegeweld as a criterion of profane versions. He has no code, so he reads it in the state of altered consciousness in order to decipher it. The sacred knowledge, which was read from the book, is not that of the character, it is only transmitted with his help, transforming the subject into a tool of language.

The analysis of allusions to The Name of the Rose shows the polemic between A. Korolev and U. Eco, because it denies the possibility to escape from the plurality of relative texts about existence with the help of ironic tolerance and an ironic attitude to any fact. The author of the novel offers two endings: the victim character escapes from Hegeweld and commits a suicide (the death of a subject in cliche meanings of everyday life); the character returns to Hegeweld's world, where his consciousness is 
changed by texts and therefore is cured of the fatal reality. The treatment offered by the clinic is the feast of the spirit as an internal game with meanings, refusal from the knowledge of truth and from the tragedy of the lack of truth.

\section{References}

1. Korolev, A.V. (2016) Dom bliznetsov: Roman-detektiv [House of the Twins: a detective novel]. Moscow: ArsisBooks.

2. Lotman, Yu.M. (1999) Vnutri myslyashchikh mirov. Chelovek - tekst-semiosferaistoriya [Inside the thinking worlds. Man - text - semiosphere - history]. Moscow: Yazyki russkoy kul'tury.

3. Morozov, I.A. \& Sleptsova, I.S. (2004) Krug igry. Prazdnik i igra v zhizni severnorusskogo krest'yanina $(X I X-X X v v$.) [The circle of the game. Holiday and Game in the life of a North-Russian peasant (19th-20th centuries)]. Moscow: Indrik.

4. Rybal'chenko, T.L. (2012) Obraznyy mir khudozhestvennogo proizvedeniya i aspekty ego analiza [An imaginative world of a work of art and aspects of its analysis]. Tomsk: Tomsk State University.

5. Russian Biblical Society. (1994) Bibliya. Knigi Svyashchennogo Pisaniya Vetkhogo $i$ Novogo zaveta: kanonicheskie [The Bible. Books of the Holy Scriptures of the Old and New Testaments: canonical]. Moscow: Rossiyskoe Bibleyskoe obshchestvo.

6. Lipovetskiy, M.N. (1997) Russkiy postmodernizm: ocherki istoricheskoy poetiki [Russian postmodernism: essays of historical poetics]. Yekaterinburg: Ural State Pedagogical University.

7. Losev, A.F. \& Asmus, V.F. (eds) (2007) Platon. Sochineniya: $v 4 t$. [Plato. Works: in 4 vols]. Translated from Old Greek. Vol. 3. Pt. 1. St. Petersburg: Spb* State University; Izd-vo Olega Abyshko.

8. Barthes, R. (1994) Izbrannye raboty: Semiotika. Poetika [Selected works: Semiotics. Poetics]. Moscow: Progress.

9. Gavrilova, E.G. (2015) [Reflection of the national world view in paremias with a component - the numeral two]. Innovatsii. Intellekt. Kul'tura [Innovations. Intelligence. Culture]. Proceedings of the XXII All-Russian (with international participation) conference. Tyumen: Tyumen Industrial University. pp. 178-180. (In Russian).

10. Gritsanov, A.A. \& Mozheyko, M.A. (eds) (2001) Postmodernizm: entsiklopediya [Postmodernism: an encyclopaedia]. Minsk: Interpresservis: Kn. Dom.

11. Korolev, A.V. (2015) Razodrannyy mekh i veter vremeni. Beseda s G. Zaslavskim [Shattered fur and the wind of time. A conversation with G. Zaslavsky]. Nezavisimaya gazeta. 26th February. [Online] Available from: http://www.ng.ru/ng_exlibris/2015-0226/2_persona.html.

12. Lotman, Yu.M. (1989) Vykhod iz labirinta [Way out of the labyrinth]. In: Eco, U. Imya rozy [The Name of the Rose]. Moscow: Knizhnaya palata.

13. Mikhaylov, A.V. (1997) Yazyki kul'tury: uchebnoe posobie po kul'turologii [Languages of culture: a textbook on cultural studies]. Moscow: Yazyki russkoy kul'tury.

14. Bakhtin, M.M. (1979) Estetika slovesnogo tvorchestva [Aesthetics of verbal creativity]. Moscow: Iskusstvo. pp. 9-191.

15. Heidegger, M. (2011) Bytie i vremya [Being and Time]. Translated from German. Moscow: Akademicheskiy proekt. 